\title{
Methodological problems and policy implications in sexual harassment research
}

\author{
JAMES E. GRUBER \\ Department of Sociology, University of Michigan, Dearborn, Michigan 48128-1491, USA
}

\begin{abstract}
This paper argues that the ability of social research to influence legal arguments and policy decisions on sexual harassment in the workplace has been stymied by several methodological problems which are shared by most major studies on the topic. Determination of the incidence of harassment and its major sub-types is difficult because of problems with sampling (e.g., response rate, sample size) and instrument construction (e.g., number or variety of harassment categories). Additionally, severity of harassment is rarely treated as a variable.

Several resolutions to these problems are presented. First, estimates of the proportion of women who have experienced harassment, as well as the proportion having experienced the major sub-types of harassment, are derived. Second, a mutually exclusive and exhaustive set of sexual harassment categories, which includes harassment types that have evolved recently from legal decisions and policy developments, is discussed. Finally, an outline of factors which might be used to assess harassment severity is presented. Resolving these issues will provide social scientists and non-scientists alike with clearer answers to the 'How much?', 'Which types?' and 'How serious?' questions about harassment.
\end{abstract}

\section{Methodological problems and policy implications in sexual harassment research}

Sexual harassment has been an important research topic for social scientists for over a decade, during which time a number of theoretical and empirical studies have been published. Despite this attention, it is nevertheless very difficult to determine from the literature with any degree of certainty the percentage of women who have experienced harassment recently, or a definitive list of the types of sexual harassment. As I will show in this paper, attempts to derive such basic information are stymied by several significant methodological problems shared by many research studies. A resolution of these problems is critical in order for social scientists to have a meaningful impact on legal and policy-related issues.

This paper has several goals: (1) to examine the various methodological problems of previous research; (2) to provide some reasonable estimates, given the limitations of the research literature, of the percentage of women who have experienced harassment, as well as the kinds of harassment they have experienced; and (3) to outline a comprehensive categorization of sexual harassment types, along with a strategy for addressing the issue of harassment 
severity. This paper has been sparked by two concerns. First, as a researcher in the field, I have encountered substantial problems in attempting to compare the results of my research to those of others. Also, as a social scientist who has consulted on more than a dozen sexual harassment lawsuits, I have discovered significant gaps in our understanding of sexual harassment. It is, for example, difficult to give straightforward testimony about the severity or the typicalness of the types of harassment a recipient has experienced.

\section{What is sexual harassment?}

Since the beginning of this decade, most research studies have used the definitions of either the Equal Employment Opportunity Commission (EEOC), or the National Organization for Women (NOW) and the Working Women Institute (WWI). According to the latter:

'Sexual harassment is any repeated or unwanted verbal or physical sexual advances, sexually explicit derogatory statements, or sexually discriminatory remarks made by someone in the workplace which are offensive or objectionable to the recipient or which causes the recipient discomfort or humiliation or which interferes with the recipient's job performance.' (cited in Brown, 1988: 451)

The EEOC guidelines are more stringent and specify that harassment exists not simply when there has been 'unwanted or repeated verbal or physical sexual advances' but when such advances have specific employment consequences, such as job loss or loss of job-related opportunities or the creation of an 'intimidating, hostile, or offensive work environment' (EEOC 1980). These definitions, or ones which are very similar, have influenced the eighteen studies analyzed below. (For example, the Canadian Human Rights Act definition of sexual harassment is nearly identical to the EEOC definition.) There are, however, differences among the studies in how these definitions are employed methodologically. A number of studies have followed the method adapted by The United States Merit Systems Protection Board (1981): on the basis of the EEOC guidelines, explicit categories of harassment (e.g., 'requests for sexual favors') were developed for a survey questionnaire and respondents were asked if they had experienced any of these forms of 'unwanted sexual attention' in the past 24 months. Other studies discussed below presented respondents with a definition and asked them to describe any experiences they had had.

While these studies have developed different methods for evoking recollections, and tabulating incidents of sexual harassment, they all share a com- 
mon definitional ground. The differences among the studies in terms of the incidence of harassment, or the number and types of harassment categories they include, are not so much a function of widely divergent conceptualizations of sexual harassment as of divergent methods of operationalizing similar conceptions of sexual harassment.

\section{What is the incidence of sexual harassment?}

Earlier non-random surveys of sexual harassment (Silverman 1976; Lindsey 1977) found very high incidence levels. More recent surveys reveal quite a different picture. The studies presented in Table 1 were selected for my study for three reasons: They are for the most part fairly recent (in the 1980's); they each employ some form of sampling strategy; and together they embrace a wide spectrum of occupations and organizations in Canada and the U.S. The eighteen surveys are categorized as cross-sectional, public-sector, privatesector, and university samples. There is considerable variation in the number of women who have experienced harassment, ranging from $75 \%$ in the study by Lafontaine and Tredeau to $28 \%$ among students in Cammaert's survey at the University of Calgary. What factors are responsible for these variations? Are women in some occupations or settings harassed more frequently than others? It appears at first glance that federal government employees experience less harassment than either State or municipal government employees. Similarly, it seems that hospital workers and flight attendants experience more harassment than women in blue-collar jobs. Also, it seems that there is less harassment on college campuses than in workplaces. Such straightforward comparisons of harassment proportions cannot be made, however, because of substantial differences in research methodology, in particular sample size, survey response rate, sample diversity, harassment frame of reference, number of harassment categories, and types of words/phrases used to elicit responses. Several of these issues have been addressed recently in excellent critical reviews (Gillespie and Leffler 1987; Lloyd 1987) which note that research samples of poor quality inhibit the generalization of research results, and diverse categorizations of sexual harassment make replication of previous studies extremely difficult.

In order to determine the impact of methodological differences on survey results, the eighteen studies were rank-ordered according to the percentage of women reporting sexual harassment and a median percentage figure was derived. This figure ( $44 \%$ ) was used to categorize the surveys as follows: those near the median ( $42-47 \%$ ), those below (under $41 \%)$, and those above ( $48 \%$ and over). Four studies are near the median (Loy and Stewart; McIntyre; USMSPB; and Griffin-Shelley), seven are above (CHRC; Schneider; Webk- 


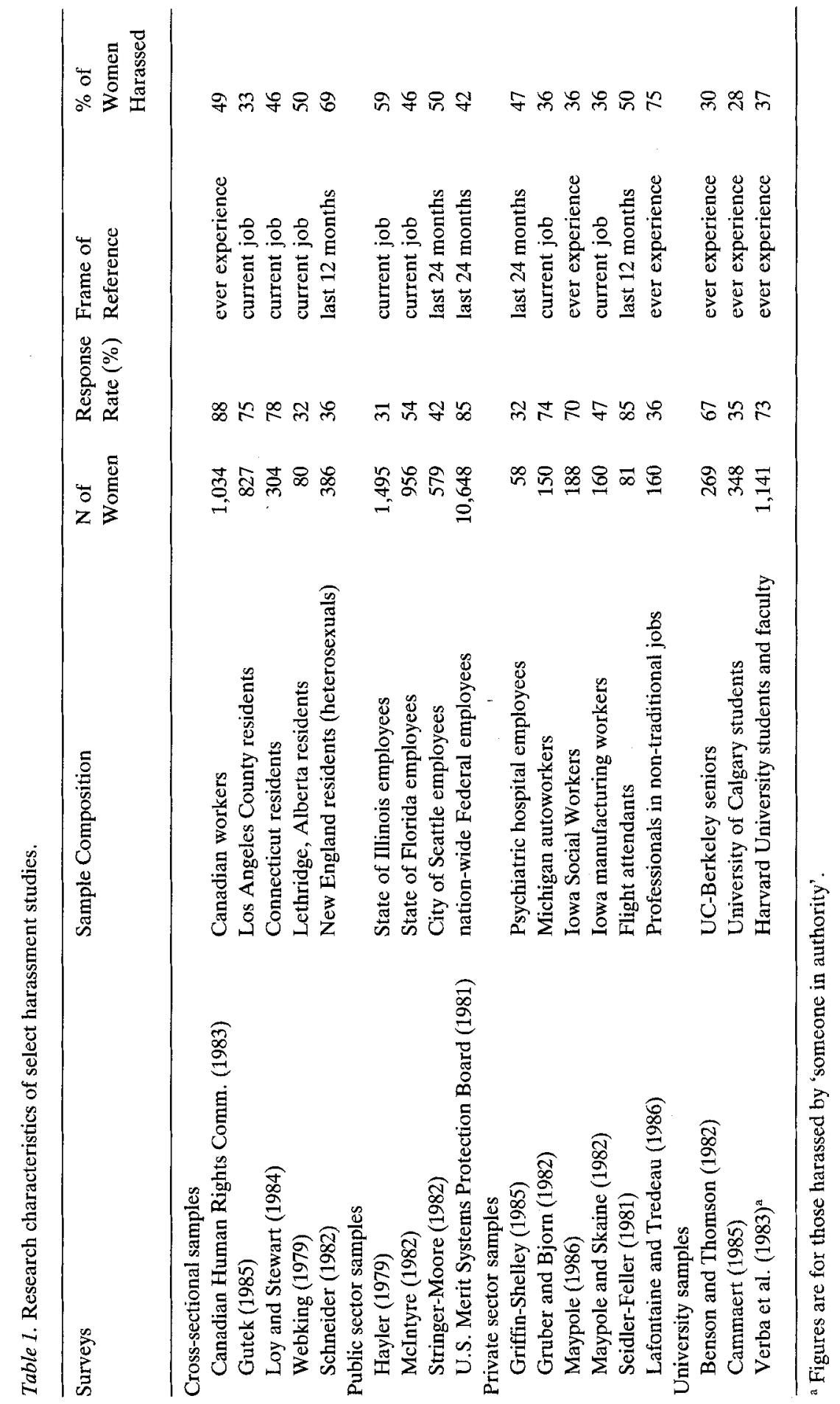


ing; Hayler; Stringer-Moore; Lafontaine and Tredeau; and Seidler-Feller), and seven are below (Gutek; Gruber and Bjorn; Maypole; Maypole and Skaine; Verba et al.; Benson and Thomson; and Cammaert). These studies were analyzed on the basis of their relationship to the median and the abovelisted methodological characteristics. The results are presented in Table 2. Pair-wise comparisons (Higher vs. Similar, and Lower vs. Similar) were made using Fisher's Exact Test to determine whether the studies whose percentages depart substantially from the median are significantly different in their methodological characteristics from those with figures near the median.

The comparisons for sample size do not yield statistically significant results: The distribution of the above-median studies is the same as that of the below-median ones. It does appear that a low response rate may inflate the report of harassment. Surveys with above-median percentages of harassment tend to have lower response rates than the studies near the median $(\mathrm{p}<0.10)$. In contrast, the response rates of studies with below-median percentages are not significantly different from the near-median ones. Harassment frame of reference - whether the respondent was asked about a harassment experience which occurred during a specific time period or at any time during her job tenure - was not significantly related to overall harassment frequency. It should be noted, however, that most studies with above-median figures are time-framed. Sample diversity, ${ }^{1}$ in contrast, is significant for one of the comparisons. It appears that samples drawn from fairly homogeneous occupational classifications or organizations tend to have significantly lower harassment rates than those drawn from more heterogeneous groups $(\mathrm{p}<0.10)$.

A final methodological issue - the number of categories that are explicitly presented in the respondents - was considered. It is possible that studies with more categories report a higher incidence of harassment than those which either present few explicit categories or else rely on answers to open-ended questions to enumerate harassment types, because the use of explicit response categories often facilitates respondent's recall of specific events (Sellitz et al. 1976: ch. 9). Our results give partial support to this hypothesis. Though above-median studies are not significantly different from the near-median studies in this regard, below-median studies have fewer categories than the near-median ones $(p<0.10)$. This suggests that studies which either offer respondents few categories (e.g., Maypole or Cammaert) or else develop categories from open-ended questions (e.g. Gruber and Bjorn, Benson and Thomson) may underestimate the actual incidence of harassment.

Though the number of near-median studies is small, it is interesting to note that three of the four have large and diverse samples, high response rates, and a large number of categories. An over-estimation of harassment rates is apparently related to a low survey response rate or, to a lesser extent, a small sample size of the use of a time frame. In contrast, one is likely to underestimate 
harassment by using either a sample with little diversity or harassment questions which have few response categories.

\section{What are the major forms of sexual harassment?}

How many different types of harassment are there? How often does each occur? It is difficult to answer these questions because a variety of categorizations are found in the research literature and different procedures are used for deriving percentages for each category. Twenty categorizations found in the selected studies are presented in Table $3 .^{2}$

Five categories from Maypole's (1986) research were excluded because they are not harassment types per se but are instead responses to rejection (see Maypole's Table 3, note f). The number of categories listed in Table 3 is actually conservative since different terms for the same phenomenon or very similar phenomena were placed in a single category. These are cited in the

Table 2. Studies of sexual harassment classified by incidence of harassment and design of study.

\begin{tabular}{|c|c|c|c|c|c|}
\hline \multirow{2}{*}{$\begin{array}{l}\text { Methodological } \\
\text { Factors }\end{array}$} & \multicolumn{3}{|c|}{ Relationship to Median ${ }^{\mathrm{a}}$} & \multicolumn{2}{|c|}{ Comparison $(p)^{b}$} \\
\hline & Above & Near $^{\mathrm{c}}$ & Below & $\begin{array}{l}\text { Above vs } \\
\text { Near }\end{array}$ & $\begin{array}{l}\text { Below vs } \\
\text { Near }\end{array}$ \\
\hline \multicolumn{6}{|l|}{ Sample size } \\
\hline Under 200 & 3 & 1 & 3 & ns & ns \\
\hline $200+$ & 4 & 3 & 4 & & \\
\hline \multicolumn{6}{|l|}{ Response rate } \\
\hline Under $50 \%$ & 6 & 1 & 2 & $\mathrm{p}<0.10$ & ns \\
\hline $50 \%+$ & 1 & 3 & 5 & & \\
\hline \multicolumn{6}{|c|}{$\begin{array}{l}\text { Harassment frame of } \\
\text { reference }\end{array}$} \\
\hline Time & 5 & 2 & 3 & ns & ns \\
\hline Job & 2 & 2 & 4 & & \\
\hline \multicolumn{6}{|l|}{ Sample diversity } \\
\hline Low & 3 & 1 & 6 & ns & $\mathrm{p}<0.10$ \\
\hline High & 4 & 3 & 1 & & \\
\hline \multicolumn{6}{|c|}{$\begin{array}{l}\text { Number of explicit } \\
\text { categories }\end{array}$} \\
\hline 5 or Less & 3 & 1 & 6 & ns & $\mathrm{p}<0.10$ \\
\hline 6 or More & 4 & 3 & 1 & & \\
\hline
\end{tabular}

The median percentage is 44 .

${ }^{b}$ Fisher's Exact Test is the basis for determining $p$. Two $\times$ two comparisons are made with Above vs. Near figures and Below vs. Near figures.

c The four percentages closest to the median by $\pm 3 \%$ percentage points represent the 'near median' category. 
notes attached to Table 3. Also, uniformity in determining percentages has been created by using total harassment incidents as the base for all of the studies. A comparison of percentages from study to study, even those using similar categories, is difficult because some studies base figures on the percentage of women in the total sample who have experienced a specific type of harassment, while others base figures on the percentage of harassed women who have experienced a specific type of harassment. I have elected the latter procedure.

On the surface, the multiple categories in Table 3 suggest that there is considerable diversity in the forms of sexual harassment among different occupational or organizational groupings. A closer analysis, however, reveals some consistency.

In the majority of the studies, the most frequently reported harassment incident includes general comments or questions of a sexual nature ('teasing/ questions/remarks'). Most of the studies which include this or a very similar item report harassment percentage around $27 \%$. One exception $-51 \%$ found by Loy and Stewart - is probably a function of the dearth of verbal harassment categories in their research. Other studies that make few distinctions between different types of verbal statements (e.g., remarks vs. requests) show that 'sexual comments' are the most frequent form of harassment and the percentages vary widely: Gutek reports $33 \%$; Webking $83 \%$; Maypole $62 \%$; Maypole and Skaine $45 \%$; Benson and Thomson $40 \%$; Cammaert $37 \%$; and Lafontaine and Tredeau $31 \%$. At the other extreme, the lowest percentages of harassment incidences are found for the 'sexual assault' category. The ten studies which include such a category show a 1-3\% range of incidence.

Between these two extremes, the variations are more difficult to interpret. Nonverbal behaviors, either 'looks/stares/gestures' or 'touching/cornering', generally have the second-highest percentages. There is considerable variation, however, in the percentage of all harassment types that these two represent. While seven studies which include a 'looks/stares/gestures' category report harassment incidences in the $19-27 \%$ range, two others have figures under $10 \%$ and another reports $39 \%$. The percentages for 'touching/cornering' are also variable. There are two clusters of percentages among the seventeen studies which include this category. Nine studies fall in the $10-17 \%$ range; six are in the $20-27 \%$ range; and one stands apart with a figure of $36 \%$.

Given the diverse categorizations, and the divergent figures for similar categories, can some determination be made of the relative occurrence of some types of sexual harassment? I believe it is possible to provide some rough estimates of several types of sexual harassment if we limit our focus in Table 3 to the sufficiently broad and recurring categories that are found among the studies having the three significant methodological characteristics presented in Table 2 (high response rate, sample diversity, and six or more substantive 


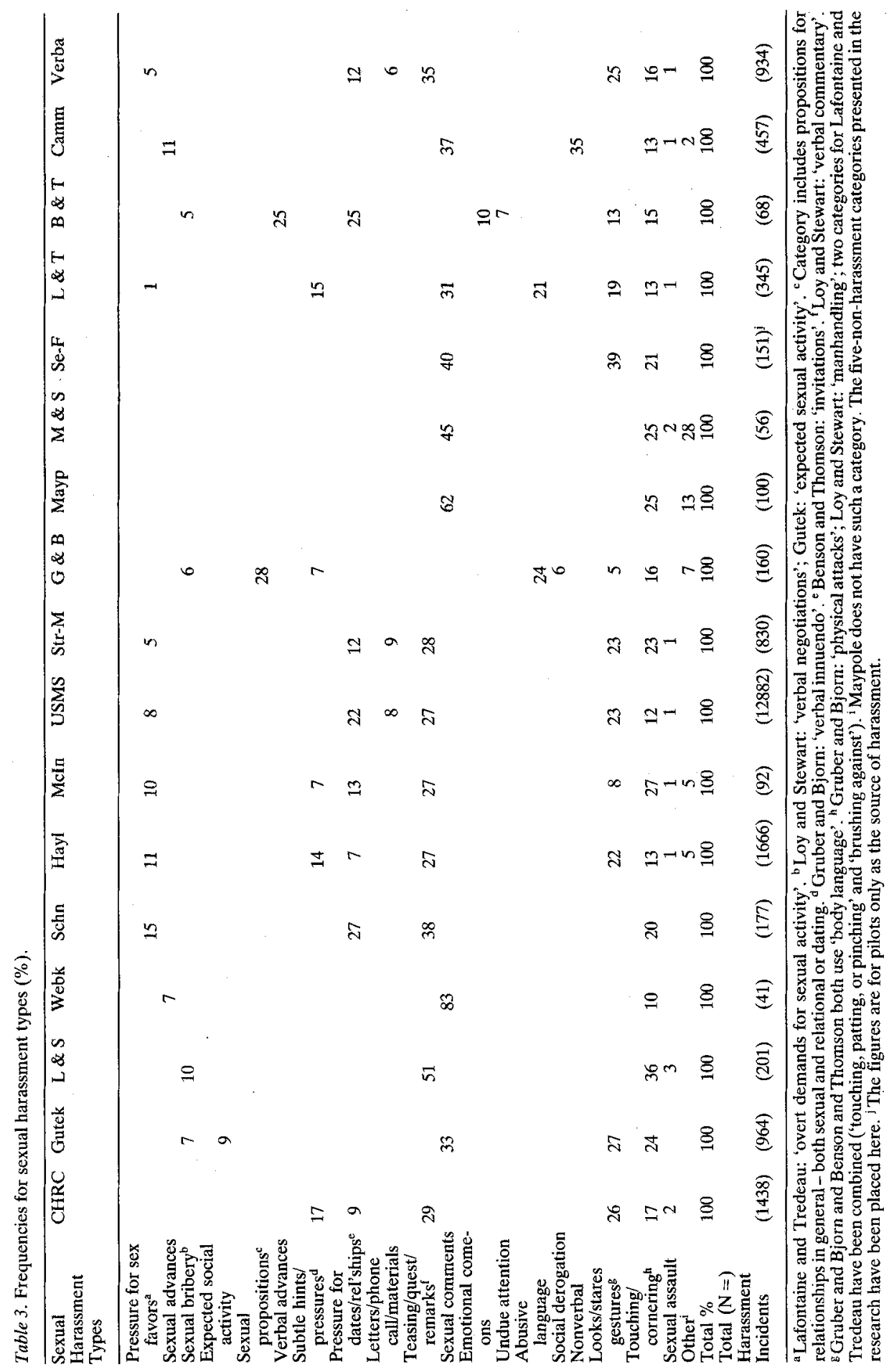


categories). There are three such studies - those by the Canadian Human Rights Commission, the United States Merit System Protection Board, and McIntyre. A fourth study, that by Verba et al., was included because it is more diverse than the other two university-based studies and its categories closely parallel those found in the other three. These four surveys contain five categories which can be compared: pressure for dates/relationships; teasing/questions/remarks; looks/stares/gestures; touching/cornering; and sexual assault.

The percentage range and the median of the percentages for the five categories are presented in Table 4. Harassful verbal behavior occurs more frequently than non-verbal behavior. One type of verbal request, pressure for dates/relationships, accounts for a slightly more than one of every ten harassment incidents. Verbal comments (teasing/...) represent approximately a quarter of harassment incidents. Among the non-verbal categories in Table 4, the incidence of harassment increases as the physical distance between the harasser and the victim increases. Sexual assault, a coercive and extended form of physical contact, occurs in one percent of all harassment incidents. Less assaultive and usually briefer forms of physical contact represent less than one-fifth of harassment experiences; and 'sexual posturing' (stares/...) account for approximately a quarter. It is interesting to note, as a summary remark, that while harassment incidents involving either unwanted requests or unwanted touching have often received the most attention from experts in the field, the results of Table 4 suggest that a substantial portion of harassment incidents are either non-solicitory or non-contact in nature.

\section{What are the problems with sexual harassment categorizations?}

Tables 3 and 4 reveal the scope of the problems to which other researchers have alluded. Though others (notably Gillespie and Leffler, and Lloyd) have criticized harassment research procedures, no one to date has explored these

Table 4. Harassment percentages from four select studies ${ }^{a}$.

\begin{tabular}{lcc}
\hline Harassment Type & Range & Median (rounded) \\
\hline Pressure for dates/relationships & $9-22$ & 13 \\
Sexual Comments & $27-35$ & 28 \\
Sexual Posturing & $8-26$ & 24 \\
Sexual Touching & $12-27$ & 17 \\
Sexual Assault & $1-2$ & 1 \\
\hline
\end{tabular}

${ }^{a}$ The range and median are based on the actual percentages in Table 3 for the four studies: Canadian Human Rights Commission, U.S. Merit System Protection Board, McIntyre, and Verba et al. 
issues in depth by analyzing the impact of methodological factors on harassment percentages or by comparing harassment categorizations. It is to this latter matter, harassment categorizations, that I now turn. Based on my own review of the research literature, as well as that of others, three central methodological problems emerge: different terms are used to describe a similar phenomenon (or, conversely, similar terms are used to denote somewhat different phenomena); harassment categories are not exhaustive and mutually exclusive; and the categories are not treated in a way that reveals variations in severity of harassment. Each problem is discussed in detail below.

\section{Labelling sexual harassment experiences}

Given the fact that harassment is a fairly new research area and that most of the eighteen studies were conducted at approximately the same time, it is not surprising that different terms are used to describe similar harassment experiences. For example, Gruber and Bjorn and Benson and Thomson use 'sexual bribery' to refer to the same experience labelled as 'verbal negotiations' by Loy and Stewart and 'expected sexual activity' by Gutek. The category 'pressure for dates/relationships' found in several studies (USMSPB, McIntyre, Hayler) is termed 'invitations' by Loy and Stewart. 'Pressure for sex favors' found in six studies is termed 'overt demands for sexual activity' by Lafontaine and Tredeau. Similarly, 'subtle hints or pressures' presented by CHRC and Hayler is termed 'verbal innuendo' by Gruber and Bjorn. The category 'verbal commentary' in Loy and Stewart is essentially the same as 'teasing/questions/ remarks' presented in six studies. Two studies (Gruber and Bjorn, and Benson and Thomson) use 'body language' to refer to what seven other studies call 'looks/stares/gestures'. This is a troublesome issue in that a reader of the literature may believe that there are many different sorts of harassment experiences until he/she reads carefully the definitions or operationalizations of terms. The lack of consistent usage of terms is a predictable problem in a new and evolving research area (Kuhn 1969). As a field of study matures, the definitions of terms, the operationalization of variables, and the development of research techniques are gradually standardized (Kuhn 1969).

\section{Mutually exclusive and exhaustive categorizations}

Even more perplexing than the lack of consistent labelling of harassment experiences is the proliferation of categories which are not mutually exclusive and exhaustive. It is very difficult to compare harassment typologies from one study to another: some categories are too broad; some too narrow; some 
studies have too few categories; others have too many of the same kind. These problems present predictable difficulties: studies with broad categorizations have lost valuable information about specific subtypes of harassment; and studies with narrow categorizations often omit logical categories of harassment found in other studies.

A cursory examination of the number of categories gives one insight into the problems of comparing harassment studies. Earlier I found (Table 2) that category number was a significant factor in determining harassment frequencies. Three studies (Webking, Seidler-Feller, and Maypole and Skaine) have only three substantive categories; Maypole has two; and Schneider and Loy and Stewart have four. In contrast, seven studies (Hayler, McIntyre, USMSPB, Gruber and Bjorn, Lafontaine and Tredeau, Verba et al., and Benson and Thomson) have seven substantive categories. One of the most obvious examples of the exhaustiveness problem is the fact that only four studies (Loy and Stewart, Gutek, Benson and Thomson, and Gruber and Bjorn) have a specific category for sexual bribery, the earliest and clearest legal standard for determining harassment.

Terms like 'sexual advances', 'verbal advances' or 'sexual comments' are too broad and do not specify the content of the message. Advances or comments may be explicit or subtle; may or may not involve a threat or promise; may be a request for a date or for a sexual favor. Broad categories do have an advantage in that they encompass nearly all possible types of harassment, thereby resolving the exhaustiveness problem and leaving only a small number of boundary (exclusiveness) issues to address. A major disadvantage of such typologies is that they underspecify the variety of harassment types. On the other hand, some categorizations are too narrow and leave gaps in our understanding of sexual harassment. The problem in this instance is one of incomplete delineation of categories: logical categories of harassment are omitted. There are several examples of this. The Benson and Thomson categories 'emotional come-ons' and 'undue attention' appear to be subtypes of a general category called 'subtle hints/pressures' which also might include 'verbal innuendos' (Gruber and Bjorn). 'Manhandling' (Loy and Stewart) and 'physical attacks' (Gruber and Bjorn) might be viewed as subcategories of a general 'sexual touching' category which could include other less-aggressive forms of behavior (e.g., arm around waist, back rubs). 'Pressure for sex favors' could be subsumed under 'sexual propositioning' since the latter includes both sexual and relational/dating pressures. 'Pressure for sex favors' itself could be subdivided into pressures involving a threat or promise ('sexual bribery') and those without threats or promises. The same comparison can be drawn between 'pressures for dates/relationships' and Gutek's 'expected social activity': her 'pressure' (involving a quid pro quo) is one of several possible forms of relational pressure, most notably badgering for a date. 
As we increase the number of categories and subcategories we also create boundary problems at a more refined level. A good example of this is the distinction between 'pressures' of various sorts and 'subtle hints/pressures'. What is a subtle pressure? Can we make such distinctions? I believe we can if specific and detailed information about the content and the context of a harassing interaction is provided. Unfortunately, surveys which use a fixedchoice format for eliciting sexual harassment data are poor at providing such information.

\section{Severity of sexual harassment}

A final problem with categorizations of sexual harassment is that most have not given consideration to the matter of harassment severity. Only three studies (USMSPB, Verba et al., and Gruber and Bjorn) have used such a variable to explore differences in the incidence of, and the responses to, sexual harassment. Severity of harassment is an important research consideration for several reasons. First, though differences in power (see Tangri et al. 1982) predict which persons are likely to be the recipients of frequent harassment, these same factors do not predict the likely recipients of severe harassment (see Gruber and Bjorn 1982). Second, as these three studies which include a severity variable have shown, the manner in which recipients respond is a function of, among other things, the severity of the harassment. In general, women respond more assertively to more severe harassment. Third, there is a range of psychological and job-related effects that are most probably related to harassment severity. With the exception of the three studies, little has been done thus far to correlate severity with effects. Fourth, severity is a function of several factors in addition to the harassing act itself. Specifically, the same act (e.g., requests for a date) may differ in severity as a result of contextual factors such as the status of the harasser, the degree of offensiveness of the request, or the frequency or duration of these requests.

Two of the three studies (USMSPB and Verba et al.) created a threecategory variable based on the extent of agreement among survey respondents that an act could be defined as 'sexual harassment'. Touching, for example, was defined by the researchers as a more severe form of harassment than dating requests because of greater consensus for the former than for the latter. Verba et al. developed a 5-point scale of severity based not only on how upsetting an incident was to a recipient but also on several contextual factors (e.g., source, duration). Since the development of these measures of severity in the early and mid-1980's there has been a considerable amount of research measuring differences in perceptions of sexual harassment. These more recent 
studies represent a fertile ground for the development of more sophisticated, contextually-based measures of harassment severity.

To date there are two types of research which tap respondent's perceptions of sexual harassment. One line of research measures perceptual differences through responses to fixed-choice survey items (e.g., USMSPB, Gutek, Stringer-Moore, Hayler). A second research vein has provided significant insight into the contextual factors which shape perceptions of sexual harassment by employing vignettes under controlled experimental conditions (e.g., Rossi and Weber-Burdin 1983). Taken together, these lines of research provide valuable information about which acts are more harassing than others and which contextual factors affect the likelihood of a specific act being perceived as 'sexual harassment'.

What are the factors that are important in research participant's perceptions of harassment? In general, touching done in a sexual manner is perceived as more harassing than verbal commentary (Terpstra and Baker 1987; Gutek et al. 1983). Also, the more explicit is the sexual content of an interaction, and the more personally-directed the behavior or comment is, the more likely it is to be perceived as harassment (Rossi and Weber-Burdin 1983; Gutek et al. 1983; Terpstra and Baker 1987). Interactions which involve a threat or a promise are perceived as especially harassing (Terpstra and Baker 1987; Reilly et al. 1982; Collins and Blodgett 1981; Rossi and Weber-Burdin 1983; Cohen and Gutek 1985). More generally, the degree of aversiveness of an interaction affects perceptions of harassment. Statements or behaviors which are insulting or denigrating are typical examples of aversive interactional content (Gutek 1985; Vogelmann-Sine et al. 1979). Finally, frequency is related to severity (Gruber and Bjorn 1986).

It is my contention that research on the causes and effects of harassment can reap substantial benefits by more fully incorporating the results of research on perceptions of sexual harassment in the development of a multi-dimensional measure of harassment severity. The definitions presented earlier (EEOC, NOW and WWI) provide an objective basis for determining types or instances of sexual harassment which are distinct from recipient's subjective definitions. In a similar manner, research on perceptions can be used to create an objective standard of harassment severity which is distinct from recipient's subjective experiences. This standard, which parallels the 'reasonable person' standard in law (Murray 1988), essentially states that severe harassment does not exist because a recipient says it does or because she has suffered specific effects; rather, harassment is what 'reasonable' others, whose perceptions have been tapped through scientific research, say it is. Such a standard benefits both the law and social science since it eliminates the problems that some recipients of harassment might have different subjective definitions of harassment (e.g. the 
'Overly-Reactive' type) or suffer unusual effects (the 'Overly-Sensitive' type) compared to others.

A research strategy such as this also has very practical policy implications as well. It is difficult to say how harassing a workplace or a specific act is without an objective standard for determining severity. Questions such as the following, which have been raised during my consulting activities speak to the need for such a standard: Is this harassment or just horseplay? Which types of interaction should we (the organization) try to eliminate - and what level of sanctions do we apply to different offensive behaviors? Is she (the recipient) overreacting? We social scientists cannot advise on these matters if we do not fully understand harassment severity ourselves.

\section{Summary and proposals}

The preceding analysis has delved into some unanswered questions in the sexual harassment literature. In this final section, some answers and proposals will be offered which hopefully will provide the basis for further research.

\section{How many women have been sexually harassed?}

A figure of $44 \%$ was derived from an analysis of eighteen studies. These studies encompass a broad variety of samples, data collection methods, and categorizations of harassment. Given these differences, as well as the fact that the range of reported harassment extends from $28 \%$ to $75 \%$, the figure of $44 \%$ should be treated as a best-estimate answer to the 'How many?' question. Using the data now available, it also seems that college campuses are less harassing than workplaces. This difference may well be due to the fact that the amount of daily exposure of women to potential harassers is less in the former, and the ability to avoid or escape harassment is greater.

The figures presented in Table 4 indicate that sexually-oriented statements account for a fourth to a third of all harassment incidents while sexual posturing represents approximately a quarter. Requests for dates or relationships and incidents involving physical contact each account for about one of every seven or eight harassment experiences. Finally, sexual assault is quite rare, occurring once per hundred harassment incidents. These parameters should assist researchers in doing some rough-estimate comparisons among harassment studies. For example, as a result of the present analysis it seems that the $51 \%$ figure for 'teasing/...' presented in Loy and Stewart is too high; and the figure of $5 \%$ for 'looks $/ .$. ' found by Gruber and Bjorn is too low. 


\section{How many types of harassment are there?}

A cursory examination of the literature reveals approximately thirty-five terms for harassment experiences. A critical analysis of these terms reduced the list to twenty (Table 3 ). These remaining categories were the basis for a mutually exclusive and exhaustive categorization of harassment. Though an explicit description of such a categorization is beyond the scope of this paper, an outline for its development is presented here. The categories of Table 3 suggest that there are three major forms of harassment, each having several sub-types: Verbal Requests, Verbal Remarks, and Non-Verbal 'Statements'.

Verbal Requests differ from Verbal Remarks in that the former are goaloriented statements which seek a sexual or social relationship. Other types of requests - for information about body measurements, sexual activity, and the like - are regarded as 'remarks'. These requests may involve threats or promises (i.e. bribery). Researchers should use care in specifying the type of pressure applied when categorizing a harassment incident. Advances which do not include a quid pro quo but nevertheless involve clear forms of pressure are termed 'Sexual Advances' or 'Relational Advances'. Finally, some requests are quite vague and may not appear to be requests at first glance. These 'Subtle Pressures' can be distinguished from other requests in that either the goal or the target of the request is initially ambiguous. In addition to the 'subtle hints/pressures' category of Table 3, this would include 'verbal innuendo', 'emotional come-ons', and most likely some responses that were placed under 'teasing/...'

Of the three forms of verbal remarks, 'Personal Remarks' are statements made directly to a woman. Most of what others refer to as 'sexual comments', 'verbal commentary', teasing/...' and 'letters and calls' fall into this category. The second type of remark differs from the first in that a woman is the object of sexually-oriented statements but the statements are made to others at work without directly adressing her. There are a number of examples of 'Sexual Objectification' in the literature, most of which involve either social derogation (rumor-spreading), or open discussion of a woman's body or sexuality among men within easy hearing distance of the victim (see Martin 1980). Lastly, there are 'Sexual Categorical Remarks' which refer to no one particular woman. Such remarks are not an attack upon a woman but upon women or womanhood in general.

Finally, there are four types of non-verbal statements, three where the act involves domination or physical contact. 'Sexual assault' is the most forceful and prolonged form of contact. Most contact is less coercive and of shorter duration - a pinch, a rub, a kiss - and is titled 'Sexual Touching'. 'Sexual Posturing' does not involve contact; rather, it is an invasion of personal space 
or privacy. Leers or stares as well as sexual gestures fall into this category. The fourth category, 'Sexual Materials', has received scant research attention and has in fact been included with 'letters and calls' in several studies. It is crucial that this type of harassment receives more attention since it fits clearly within the bounds of recent court decisions involving 'hostile environment' forms of harassment (see Murray 1988 for an excellent discussion). 'Materials' are of two sorts: demeaning pictures, posters, cartoons, and the like of women; and the conspicuous profanation of women's personal items (e.g., sanitary pads, underwear).

\section{What is severe harassment?}

Research on perceptions of sexual harassment has shown that some types of acts are more apt to defines as harassment than others. In addition, there are several contextual factors that affect the probability that a specific act will be defined as harassment. On the other hand, it appears that Categorical Remarks and Sexual Materials are viewed as low-severity forms. Sexual Advances are viewed with greater disapproval than Relational Advances; and Sexual Touching is more harassing than Sexual Posturing.

While the context of the situation is unlikely to affect the severity of bribery or assault - they are highly severe in and of themselves - observer's knowledge of contextual information is certainly apt to change their assessment of the severity of most other harassing acts. I believe there are five contextual factors which affect severity. The source of the act is an important factor. The research literature shows clearly that a given act is more apt to be defined as harassment when it is done by someone in a position of authority. The duration or frequency is important, especially for 'hostile environment' forms of harassment. The courts have argued that such forms must be sufficiently pervasive and enduring before they can be regarded legally as harassment (Murray 1988). A third factor is the directness of the act. Physical contact increases the likelihood that a verbal statement will be perceived as harassment. Intrusions into personal space or intimate privacy are less direct than physical contact but more direct than offensive acts directed at others (e.g., a woman who sees other women being harassed) or at no one in particular (e.g., pornographic posters displayed in the workplace).

There are two other factors which affect harassment severity: degree of aversiveness and degree of threat. Acts such as assault or bribery are extremely aversive and threatening and affect women's emotional and economic wellbeing. Aside from these, however, most other acts of harassment vary according to the amount of aversiveness or threat involved. Verbal statements vary in 
adversiveness depending on the types of words or references included in the message; visual materials vary in the degree to which they contain graphic, demeaning displays of women's bodies or sexuality. In a similar manner, the same harassing act may be more or less threatening depending on the context. Specifically, the anger or rage behind the action, the number of people who participate in the harassment, or the ability of the victim to avoid the harasser are several notable factors which need to be addressed more extensively. Researchers need to develop continua for each aspect of harassment severity by conducting more refined studies on perceptions of sexual harassment. Ideally, the results of such research will generate 'ideal type' examples for each continuum which can be used as references for understanding the various dimensions of a harassment experience.

\section{How can research inform policy?}

The 1980's witnessed the evolution of legal and social science definitions and conceptualizations of sexual harassment. Developments in the law, however, have not been paralleled systematically by changes in categories or measures of harassment by researchers. This lack of correspondence has created problems for legal experts and researchers alike: legal experts lack the ability to differentiate clearly among work environments or interactions in terms of their 'harassfulness'; and researchers have frequently not asked respondents about workplace occurrences which the law regards as sexually harassing. There are at least two ways in which a closer correspondence between law and social science can be developed.

First, since sexual harassment claims are generally made by one or more individuals against an organization, researchers should provide legal experts with a clearer understanding of the organizational factors which are associated with the incidence of harassment. For example, though the argument that blue collar environments contain a greater variety of offensive sexually-oriented behaviors or materials than white-collar workplaces has no empirical foundation, it has been used as a basis for repudiating the claims of a plaintiff (see, for example, Rabidue vs. Osceola Refining Co. 1984). Thus my ability to testify as an expert witness has sometimes been challenged by defense counsel on the ground that my published research makes me an expert only in the area of autoworker sexual harassment! In addition, there are several other factors which may affect the extent of sexual harassment within organizations. While some have received considerable research attention (e.g., workplace gender ratios, sex of immediate supervisor, gender dominance of an occupation), other factors which potentially tap sex discrimination have been understudied 
(e.g., occupational mobility patterns, economic inequality, ratios of attrition/ firing for men and women). Together, these factors would enable researchers and policy makers alike to identify the types of organizations or work environments which are apt to be 'harassment-prone'.

Secondly, researchers can provide policy makers with information about non-discriminatory and non-structural aspects of workplaces that are correlated with the incidence of harassment. Gutek (1985) suggested that the occurrence of sexual harassment may be related to 'unprofessional ambiance'. Specifically, she hypothesized that environments where a number of employees drink on the job, have antagonistic relationships with their coworkers, or attempt to undermine productivity or efficiency are likely to experience greater problems with sexual harassment than other workplaces. The impact of unprofessional or low-morale environments on the incidence of sexual harassment has not yet been researched.

Finally, researchers need to expand the number or types of categories of sexual harassment they use to include those regarded as harassment under the law. I noted, for example, that several previous studies did not ask respondents about quid pro quo harassment (sexual bribery). Recent legal definitions have included several forms of 'environmental harassment'. The incidence and impact of sexual objectification or sexual materials has received little coverage by social researchers. Similarly, research has focused on the direct or personal harassment of an individual woman while giving little consideration to the impact that the harassment of other women in the workplace has on her.

\section{Acknowledgement}

I am indebted to those at the Center for Research on Women at Wellesley College for their support and encouragement during my sabbatical, Fall 1988.

\section{Notes}

1. 'Diversity' is the degree to which a research sample encompasses a variety of workplaces and/or occupational classifications.

2. Figures for Griffin-Shelley are not presented because a breakdown of figures is not given in his research paper.

\section{References}

Benson, D. and G. Thomson (1982). 'Sexual harassment on a university campus: the confluence of authority relations, sexual interest, and gender stratification,' Social Problems 29: 236-51. 
Brown, N. (1988). 'Meritor Savings Bank vs. Vinson: clarifying the standards of hostile working environment sexual harassment,' Houston Law Review 25: 441-70.

Cammaert, L. (1985). 'How Widespread is Sexual Harassment on Campus?' International Journal of Women's Studies 8: 388-97.

Canadian Human Rights Commission (CHRC) (1983). 'Unwanted Sexual Attention and Sexual Harassment,' Montreal: Minister of Supply and Services of Canada.

Cohen, A. and B. Gutek (1985). 'Dimensions of perceptions of socio-sexual behavior in a work setting,' Sex Roles 13: 317-27.

Collins, E. and T. Blodgett (1981). 'Sexual harassment: some see it, some won't,' Harvard Business Review 59: 77-95.

Dolecheck, C. and M. Dolecheck (1983). 'Sexual harassment: a Problem for Small Business,' American Journal of Small Business 7(3): 45-50.

Equal Employment Opportunity Commission (1980). 'Guidelines on Discrimination because of Sex,' 29CFR Part 1604. Federal Register 45(210): November 10.

EEOC Policy Guidance (1988). 'EEOC Gives Guidance on Current Issues of Sexual Harassment,' Employment Practices, 6472-89.

Faley, R. (1983). 'Sexual harassment: critical review of legal cases with general principles and preventive measures,' Personnel Psychology 35: 583-600.

Gillespie, D. and A. Leffler (1987). 'The politics of research methodology in claims-making activities: social science and sexual harassment,' Social Problems 34: 490-508.

Griffin-Shelley, E. (1985). 'Sexual harassment: one organization's response,' Journal of Counseling and Development 64: 64-73.

Gruber, J. and L. Bjorn (1982). 'Blue collar blues: the sexual harassment of women autoworkers,' Work and Occupations 9: 271-98.

Gruber, J. and L. Bjorn (1986). 'Women's responses to sexual harassment: an analysis of sociocultural, organizational, and personal resources models,' Social Science Quarterly 67: $814-26$.

Gruber, J. and L. Bjorn (1987). 'Perspectives on sexual harassment,' Paper presented at the annual meetings of the North Central Sociological Association. Cincinnati, Ohio (May).

Gutek, B. (1985). Sex and the Workplace. Jossey-Bass: San Francisco.

Gutek, B. and C. Nakamura (1982). 'Gender roles and sexuality in the world of work,' in E. Allgeier and N. McCormick (eds.), Changing Boundaries, Palo Alto, California: Mayfield.

Gutek, B. and C. Nakamura (1982). 'Sex ratios, sex-role spillover, and sexual harassment of women at work,' Journal of Social Issues 38: 55-74.

Gutek, B., B. Morasch, and A. Cohen (1983). 'Interpreting socio-sexual behavior in a work setting,' Journal of Vocational Behavior 22: 30-48.

Hayler, B. (1979). 'Report of Illinois Task Force on Sexual Harassment,' Testimony before the State of Illinois Judiciary Committee: March 4.

Jensen, I. and B. Gutek (1982). 'Attributions and assignment of responsibility for sexual harassment,' Journal of Social Issues 38: 121-36.

Kuhn, T. (1969). The Nature of Scientific Revolutions. Chicago: University of Chicago Press.

Lafontaine, E. and L. Tredeau (1986). 'The Frequency, Sources, and Correlates of Sexual Harassment Among Women in Traditional Male Occupations,' Sex Roles 15: 433-41.

Lindsey, K. (1977). 'Sexual harassment on the job,' Ms. (November); 46-8.

Lloyd, R. (1987). 'Research Problems in the Study of Sexual Harassment,' Paper presented at the annual meetings of the American Sociological Association. Chicago (August).

Loy, P. and L. Stewart (1984). 'The Extent and Effects of the Sexual Harassment of Working Women,' Sociological Focus 17: 31-43.

McIntyre, D. (1982). 'Sexual Harassment in Government: The Situation in Florida and the Nation.' Tallahassee: Florida State University dissertation. 
MacKinnon, C. (1979). Sexual Harassment of Working Women: A Case of Sex Discrimination. New Haven: Yale University Press.

Martin, S. (1980). Breaking and Entering: Policewomen on Patrol. Berkeley: University of California Press.

Maypole, D. (1986). 'Sexual Harassment of Social Workers at Work.' Social Work 31: 29-34.

Maypole, D. and R. Skaine (1982). 'Sexual Harassment of Blue Collar Workers,' Journal of Sociology and Social Welfare 9: 682-95.

Murray, P.J. (1988). 'Employer: Beware of 'Hostile Environment' Sexual Harassment,' Duquesne Law Review 26: 461-84.

Rabidue vs. Osceola Refining Co, 584 F. Supp. 419, 432-3 (E.D. Mich. 1984).

Reilly, T., S. Carpenter, V. Dull, and K. Bartlett (1982). 'A Factorial Survey Technique: An Approach to Defining Sexual Harassment on Campus,' Journal of Social Issues 38: 99-110.

Rossi, P. and E. Weber-Burdin (1983). 'Sexual Harassment on the Campus,' Social Science Research 12: 131-58.

Rowe, M. (1981). 'Dealing with Sexual Harassment,' Harvard Business Review 59: 42-6.

Safran, C. (1976). 'What Men do to Women on the Job: A Shocking Look at Sexual Harassment,' Redbook (November): 149, 217-23.

Schneider, B. (1985). 'Approaches, Assaults, Attractions, Affairs: Policy Implications of the Sexualization of the Workplace.' Population Research and Policy Review 4: 93-113.

Schneider, B. (1982). 'Consciousness about Sexual Harassment Among Heterosexual and Lesbian Women Workers,' Journal of Social Issues 38: 75-98.

Sellitz, C., L. Wrightsman, and S. Cook (1976). Research Methods in Social Relations. New York: Holt Rinehart and Winston.

Silverman, D. (1976). 'Sexual Harassment: Working Women's Dilemma,' Quest: A Feminist Quarterly 3(3): 15-24.

Stringer-Moore, D. (1982). Sexual Harassment in the Seattle City Workforce. Seattle: Office for Women's Rights.

Tangri, S., M. Burt, and L. Johnson (1982). 'Sexual Harassment at Work: Three Explanatory Models,' Journal of Social Issues 38: 33-54.

Terpstra, D. and D. Baker (1987). 'A Hierarchy of Sexual Harassment.' Journal of Psychology 121: 599-605.

United States Merit Systems Protection Board (USMSPB) (1981). Sexual Harassment in the Federal Workplace. Washington, D.C.: Government Printing Office.

Verba, S., J. DiNunzio, and C. Spaulding (1983). 'Unwanted Attention: Report on the Faculty Council, Harvard University.

Vhay, M. (1988). The harm of asking: toward a comprehensive treatment of sexual harassment,' University of Chicago Law Review 55: 328-62.

Vogelmann-Sine, S., E. Ervin, R. Christensen, C. Warmsun, and L. Ullmann (1979). 'Sex differences in feelings attributed to women in situations involving coercion and sexual advances,' Journal of Personality 47: 420-31.

Walshok, M. (1981). Blue-Collar Women: Pioneers on the Male Frontier. Garden City, N.J.: Anchor Books.

Webking, E. (1979). A Study of Sexual Harassment in Lethbridge. Lethbridge: Citizen's Human Rights Council. 